\title{
Correction to: Progressive multifocal leukoencephalopathy in rituximab-treated rheumatic diseases: a rare event
}

\author{
Joseph R. Berger ${ }^{1} \cdot$ Vineeta Malik ${ }^{2} \cdot$ Stuart Lace $^{3} \cdot$ Paul Brunetta $^{4} \cdot$ Patricia B. Lehane $^{3}$
}

Published online: 10 April 2018

(C) The Author(s) 2018

\section{Correction to: Journal of NeuroVirology https://doi.org/10.1007/s13365-018-0615-7}

The article "Progressive multifocal leukoencephalopathy in rituximab-treated rheumatic diseases: a rare event," written by Joseph R. Berger, Vineeta Malik, Stuart Lacey, Paul Brunetta, and Patricia B. Lehane, was originally published electronically on the publisher's internet portal (currently SpringerLink) on 5 March 2018 without open access.

With the author(s)' decision to opt for Open Choice, the copyright of the article changed on 6 April 2018 to (c) The Author(s) 2018 and the article is forthwith distributed under the terms of the Creative Commons Attribution 4.0 International License (http://creativecommons.org/licenses/ by/4.0/), which permits use, duplication, adaptation, distribution, and reproduction in any medium or format, as long as you give appropriate credit to the original author(s) and the source, provide a link to the Creative Commons license, and indicate if changes were made.

The online version of the original article can be found at https://doi.org/10. 1007/s13365-018-0615-7

Joseph R. Berger

joseph.berger@uphs.upenn.edu

Vineeta Malik

vineeta.malik@parexel.com

Stuart Lacey

stuart.lacey@roche.com

Paul Brunetta

paul.brunetta@junotherapeutics.com
Patricia B. Lehane

patricia.lehane@roche.com

1 Department of Neurology, Perelman School of Medicine, University of Pennsylvania, 3400 Convention Avenue, Room 765, Philadelphia, PA 19104, USA

2 F. Hoffmann-La Roche, Ltd., Basel, Switzerland

3 Roche Products Ltd., Welwyn Garden City, UK

4 Genentech, Inc, South San Francisco, USA 